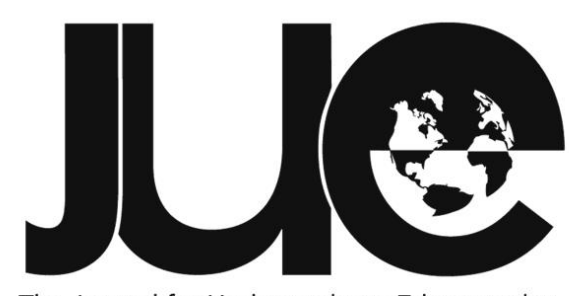

The Journal for Undergraduate Ethnography

\title{
Island Empowerment as Global Endowment: Understanding Hawaiian Adaptive Cultural Resource Management
}

\author{
Evelyn Cornwell \\ Saint Mary's College, ecornwell01@saintmarys.edu
}

\section{ABSTRACT}

Based on fieldwork and interviews with academics, activists, government officials, and indigenous alaka'i (practitioners) involved in the revival of traditional fishponds and ahupua'a (land -based management systems), I provide a case study of the politics of cultural resource management on two islands in Hawai'i. Analyzing the intersections of identity, community, education, and spirituality as they influence indigenous sciences of sustainable resource management, I underscore themes in cultural resource management, historically based restoration, Community Based Subsistence Fishing Areas (CBSFAs), and Traditional Ecological Knowledge (TEK), particularly focusing on the merits of combining these methods to create an adaptive resource management style. According to informants' understandings of place, culture, and politics in their own lives, the ideal model for a sustainable global future should be based on an indigenous place-based model of "adaptive" cultural resource management. 
To our ancestors' credit, man - I mean, they were the future scientists and now we're trying to reinvent that. (Interviewee 2)

It's customized to the place and that's really the essence of traditional fisheries management... it's a very adaptive based management... I would say the main thing that people need to understand is that you don't just manage for the resource; you manage people and resources together. (Interviewee 4)

$\mathrm{n}$ a time when the world is facing ecological crisis and global cultural assimilation, steps need to be taken to prevent further loss of biodiversity and cultural diversity. As anthropologists, we recognize that culture and nature go hand-in-hand and it is vital to preserve them both. Traditional Hawaiian management of fishponds similarly strives towards such preservation by using a combination of traditional ecological knowledge and cultural resource management. The National Marine Fisheries Service of the United States, a division of the National Oceanic and Atmospheric Administration (NOAA), has slowly progressed toward using more sustainable practices in resource management, including fisheries (National Oceanic and Atmospheric Administration 2018). Yet, funding for fisheries has declined by $77 \%$ (University of British Columbia 2018), and over 75\% of the world's fisheries are overfished (Leonard 2007, 4:14). This decline in funding immediately affects Pacific small islands and low-income coastal communities, and it more gradually affects the global community as fisheries provide $17 \%$ of human diets and create livelihoods for up to $12 \%$ of the world's population (University of British Columbia 2018).

Traditional Hawaiian management of fishing included social and cultural control that effectively sustained resources. The Hawaiian ahupua'a, an adaptive management system based on resource availability and fluctuation, was established in the fifteenth century for land division and socioeconomic organization. Ahupua'a regulated fishing activities and catch distribution using kapu, or rules. This required cognizance of lunar and seasonal cycles and their effect on resources. Konohiki, or land agents, enforced kapu for ali't (chiefs) and received advice from kupuna (elders) along with po'o lawai'a (master fishermen). Master fisherman underwent years of training before obtaining the role of an advisor. This extensive training led to high sensitivity toward environmental changes, garnering them the title "sentinels of the ecosystem" (Bambridge 2016, 180). Rules included understanding spawning cycles and avoiding fishing during those times to protect supply. This allowed Hawaiians to subsist off their resources for millennia (Bambridge 2016, 179-180).

The traditional Hawaiian system of fishing began to collapse after the introduction of the Māhele (land ownership) system in 1848 and, by 1900, all konohiki rights had been repealed and fishing was opened to all persons. Shorelines became spots for tourism and recreation (Bambridge 2016, 181). Contemporary management in Hawai'i is based on government resource managers, which means that strategies focus on maximum yield and species conservation at current levels (Bambridge 2016, 182). Focus on indigenous resource management was diminished throughout colonization and only recently reclaimed as a process to promote sustainability and prevent further deterioration of fisheries.

In another post-colonial context, the Maori people of New Zealand successfully combined indigenous cultural knowledge into present-day legal structures. They claimed legal personhood for the river Waikato (Ruru 2012, 118). Having always respected the river as part of human and spiritual life, the Maori found a way to adapt corporate law to their local kinship and spiritual system (wherein the river is both a body and a life force) in order to foster a sustainable future for the Waikato. This legal recognition of the right to water as the right to identity has inspired other indigenous claims. 
The case of the Quechua fisher folk at Lake Titicaca provides another example of indigenous resource management coexisting with national legal frameworks. The anthropologist Ben Orlove recorded how local management incorporated fishing into their kinship. Their respect for the fish allowed them to preserve their culture and livelihoods along with abundant and diverse fish stocks (Orlove 2002). This case demonstrates a system of longterm sustainability, which functioned relatively unhindered by government officials. These successful models of long-term sustainable resource management point to the need for government resource managers to pay attention to local, place-based, cultural understandings of sustainability.

Very little ethnographic research among Hawaiian fisheries' management has been conducted, which restricts the utilization of indigenous resource management in policy making. Speaking with indigenous groups opens a dialogue between policy managers, indigenous practitioners, and the general public about the merits of indigenous resource management on a larger scale. Efforts in Hawai'i have begun to combat fisheries' depletion, but challenges persist (Bambridge 2016, 178). Including the voices of Native Hawaiians, government officials, academics, and activists will improve upon existing accomplishments and continue to push fisheries management toward sustainable practices.

Below I argue that fishpond practitioners provide an important model of indigenous place-based "adaptive" cultural resource management and, as mentioned earlier, ethnographies of indigenous resource management elsewhere support my claims. Adaptive here means continuously customizing management practices by actively evolving, growing and incorporating varied methodologies into them. Cultural resource management includes "managing cultural resources... [such as] important sites, objects, and places" under a legal framework to preserve and maintain cultural heritage (Encyclopedia.com 2019). Cultural resource management gives indigenous peoples the opportunity to legally protect meaningful resources that contribute to their identity. Melissa Nelson explains that Traditional Ecological Knowledge (TEK) of indigenous peoples preserves biological diversity and creates "complex reciprocal relationships" between their cultures and the environment (2008, xxi). She states that Indigenous Knowledge, defined as "distinctive bodies of knowledge, which have evolved over many generations within their particular ecosystem, and define the social and natural relationships with those environments," is a crucial point when it comes to TEK (Nelson 2008, 45). This Indigenous Knowledge, capitalized to emphasize the importance of these epistemological claims, lies within communities, not individuals or written legislation, and reflects a collectivity of people and the environment (Nelson 2008, 45-46). As stated in the Rahui, "integrating Native Hawaiian traditional ecological knowledge (TEK) and traditional practices into contemporary marine management is an important element [of sustainable resource management] (Bambridge 2016, 178)."

As discussed by Tony Pitcher and Mimi Lam in "Fishful Thinking" (2010, 1), sustainability hinges on a composite management strategy of ecosystem-based management and historically based restoration. Ecosystem-based management comprehensively focuses on ecosystem links to make sure all interconnecting marine resources maintain healthiness (Pitcher and Lam 2010, 6). Historically based restoration means compiling data from management strategies such as Community Based Subsistence Fishing Areas (CBSFAs) and TEK to learn from and implement more successful strategies (Pitcher and Lam $2010,8)$. Pitcher and $\operatorname{Lam}(2010,8)$ argue that understanding the history of a fishery is necessary to construct a meaningful restoration strategy. My research traces the history of ahupua'a and its use along the coast of Hawai'i for a more extensive look into fishpond history.

Integrating the ideas of cultural resource management, historically based restoration, CBSFAs, and TEK will create more sustainable management of fisheries. Combining methods that have shown some success on their own will allow for greater success overall once working 
in cohesion. As Levine (2014) indicated in his study of CBSFAs, it is important to bridge the gaps between locals and officials in order to create more smoothly functioning legislation. Teaching indigenous methodologies in schools and throughout fisheries could help to inform future generations of the sustainable model built into indigenous management practices and its applicability to today's resources.

\section{Methodology}

I traveled to O'ahu during the summer of 2018 and collected data on Hawaiian fisheries management, specifically fishponds, in order to understand the intersections of cultural resource management, historically based restoration, CBSFAs, and TEK to create sustainable ecologies. Throughout an eightweek period, I continually interviewed and met with fishpond practitioners, government officials, academics, activists and oral history curators. Throughout my fieldwork, I engaged in 13 formal and 2 informal interviews with willing participants of the study (see chart).

Participants were selected from five different fishponds, with six fishpond practitioners participating. These participants provided a range to compare and contrast fishpond management styles. Three participants from government agencies were selected from departments focused on fisheries and water resources. Government participants provided information on current fisheries management and the plausibility of policy changes. Three academic participants were selected from fields of indigenous and/or cultural studies, with two opting for informal interviews. These participants provided a theoretical context and assisted in finding sources. Activist participants often intersected with fishpond practitioners and provided insight on the current focal points of indigenous activism. The five indigenous activists included in the chart are those who repeatedly mentioned activism as a large part of their identity throughout their interview. This does not mean other interviewees were not proponents of indigenous activism; instead, it means this point did not come up as frequently with the interviewees not listed as indigenous activists. Interviewing four oral history curators was particularly fruitful. Searching online revealed the challenge of finding detailed information about fishponds. Interviewee 10 explained that this was not uncommon: "it's really hard. It's a lot of people having these stories or it's just somewhere, I don't know how to search for it." This lack of online information made research especially difficult unless it was done in the field, which outlines the importance of oral tradition to indigenous Hawaiians.

\begin{tabular}{ll}
\hline Chart of interviewees & \\
\hline $\begin{array}{l}\text { Indigenous fishpond } \\
\text { practitioners }\end{array}$ & $\begin{array}{l}\text { Interviewee 1, 2, } \\
\text { (includes two persons), } \\
10, \text { \& 11 } \\
\text { Interviewee 6, 8, \& 9 } \\
\text { povernment agency }\end{array}$ \\
Academic participants & $\begin{array}{l}\text { Interviewee 4 \& two } \\
\text { informal (not noted in } \\
\text { text) }\end{array}$ \\
Indigenous activists & $\begin{array}{l}\text { Interviewee 4, 5, 6, 10, } \\
11, \text { \& 12 }\end{array}$ \\
Oral history curators & $\begin{array}{l}\text { Interviewee 1, 3, 10, \& } \\
11\end{array}$ \\
\hline
\end{tabular}

\section{Site Description}

To understand Hawaiian fishpond management, it is important to have a comprehensive description of these areas, which I gained from interviews $1,2,4$ and 5 . In these interviews, most of the language used by fishpond practitioners includes technical and scientific terms. Because these scientific terms are continually used to describe fishponds, this paper retains similar terminology. For detailed definitions of the Hawaiian vocabulary included in this document, please refer to Appendix A.

Hawaiian fishponds have kuapā (walls) surrounding the perimeter that extend into the water (see figure 1). Fishponds contain brackish water, and these ponds are designed to contain a plethora of nutrients. The mix of saltwater and freshwater produces nitrogen that then creates blooms of limu (algae). Algae is vital to the life of the pond because microalgae feeds phytoplankton and little fish within the pond. Fish enter the pond through mākāhā (sluice gates) in the wall surrounding the pond (see figure 2). During low tide, algae rich water flows out of the pond and into the ocean. This 


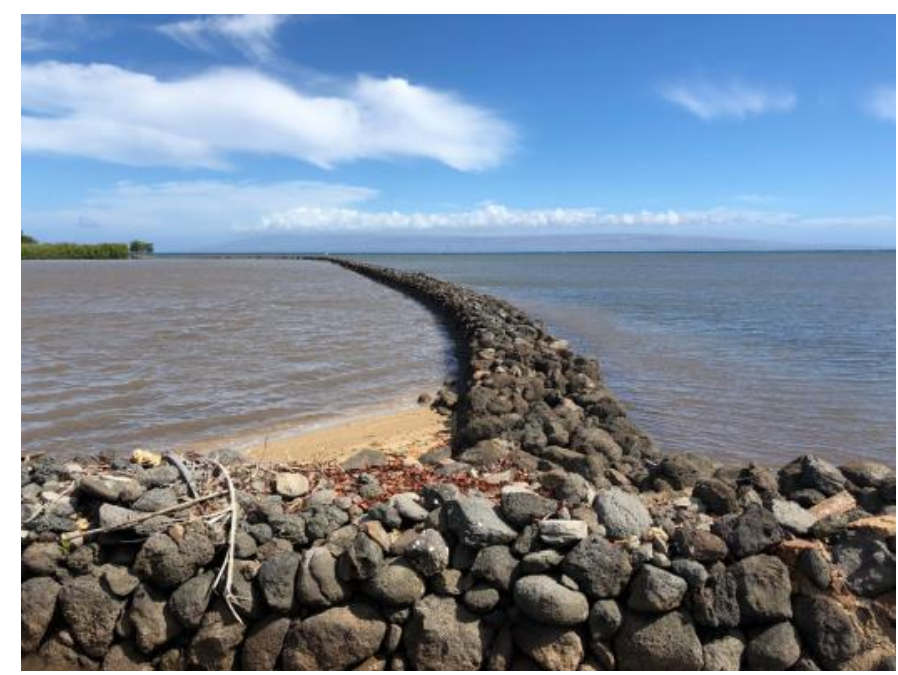

Figure 1 - Kuapā (walls) built using the traditional dry-stack method on Moloka'i. Photo by Evelyn Cornwell.

attracts small, hungry fish which enter through the gates. Clean freshwater entering into the pond is necessary for the algae to flourish and attract fish. Without this algae, the pond would not be self-sustaining and practitioners would need to feed the fish. Fishpond practitioners select herbivorous fish to avoid competition and enable the fish to thrive.

There are five known ways to construct traditional Hawaiian fishponds. One is built in the mountains and is composed of freshwater. Similarly, another fishpond is a midland pond with freshwater still coming from the mountains. None of the fishponds visited fit these descriptions. The other three types are constructed close to the shore. One is named a kuapā loko (walled in) because it is right on the shore (see figure 3). Being on the shore connects this fishpond to both land and ocean. Most of the fishponds discussed fit this model. Another fishpond fits the model of a pu'uone. A pu'uone has a channel from the fishpond to the ocean, but still has a freshwater input. During low tide, algae rich water from the fishpond flows down the channel and into the ocean to attract fish. During high tide, saltwater from the ocean flows up the channel and into the fishpond, creating the necessary mix of saltwater and freshwater to sustain the pond. The fifth fishpond is called 'umeke, or fish-trap. It is built on the shoreline and the walls contain u-shaped openings. When high tide comes in, fish enter the openings in the wall; as low tide goes out, the fish get trapped in these structures. People then harvest the trapped fish. No 'umeke style fishponds remain on O'ahu, but there is one on the Big Island.

Most fishponds contain keiki ponds (guppy ponds). After fish spawn in the larger pond, practitioners collect the babies and put them in a separate pond to increase their survival rates. Once these baby fish reach a juvenile state, they get reintroduced into the adult pond. Most of the five fishponds visited are currently restoring keiki ponds back to functionality.

In order to understand fishpond sites better, knowledge about the traditional land tenure system in Hawai'i is required. Interviewee 4 shared some of the results from her own interviews to elaborate on traditional Hawaiian management of resources.

So ahupua'a is a traditional land division and then a larger version is a moku, which is a region or district - and so these maps would show different ahupua'a, and the traditional names and people would claim them not by TMK [the Tax Map Key established by the government] but by the name of that land...it's basically from the shoreline to the edge of the reef. So that ahupua'a belonged to the people that live on that land and it was managed by a konohiki, and a konohiki in more customary ancient times was the person that had the knowledge of the fishery, of the reproductive cycles of the fish and all these things. (Interviewee 4)

An ahupua'a can stretch from the mountaintop

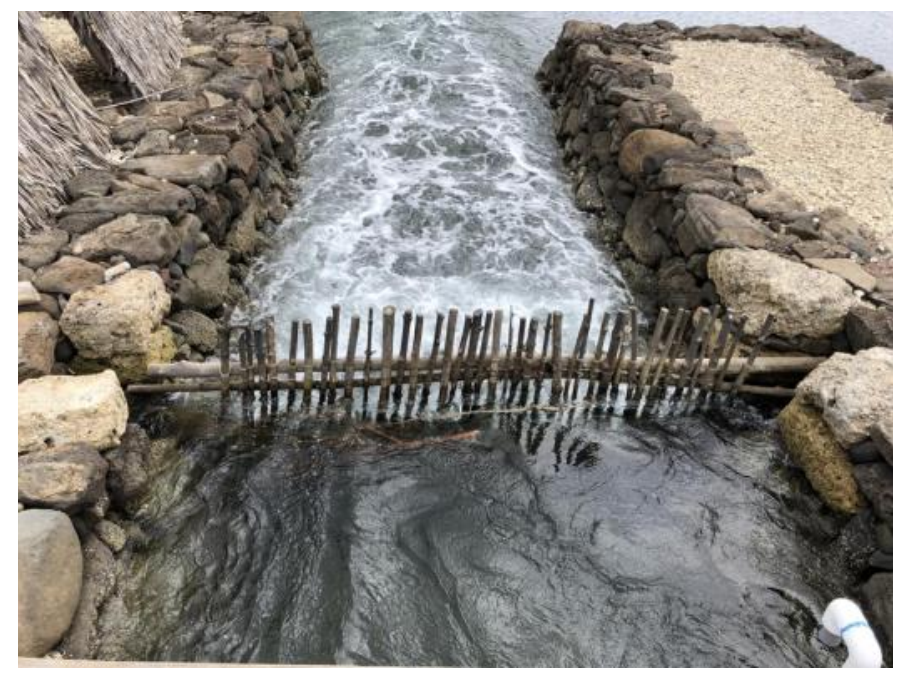

Figure 2 - Channel with mākāha (sluice gate) leading into fishpond A from the ocean at high tide. Photo by Evelyn Cornwell. 


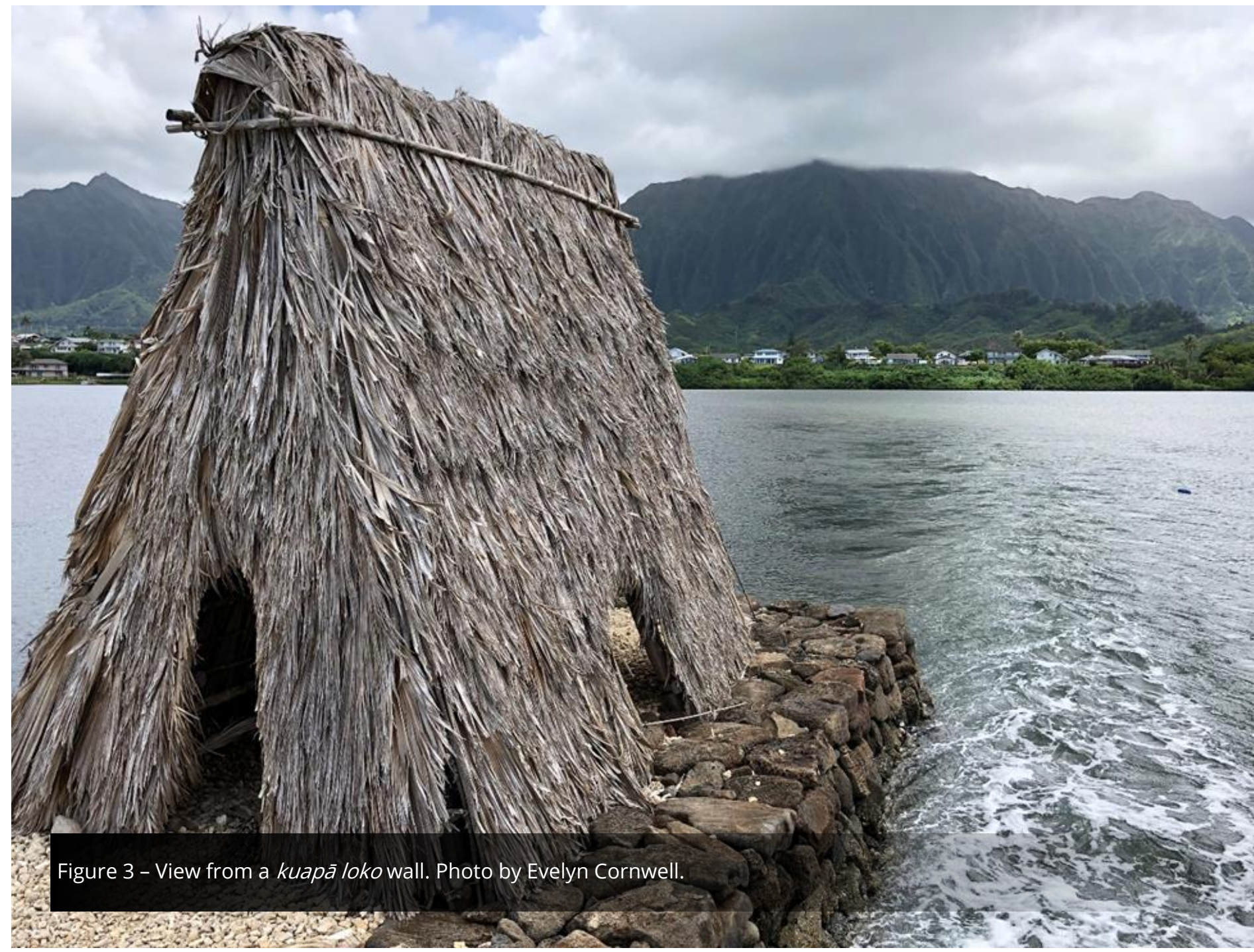

out into the ocean. This marks the resources which people in that ahupua'a have access to, including fish out in the ocean. In a perfectly functioning ahupua'a, the mountain "soaks up moisture from the clouds which seeps down through the rock and re-emerges at the pond" (Interviewee 1). The water from the

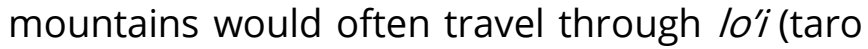
patches) before reaching the fishpond. In the process, the water would pick up rich nutrients from the soil of $10^{\prime}$; , and those nutrients would become a part of the fishes' diet.

As foreigners attempted to gain land in Hawai'i, the Māhele system was established by Kamehameha III in 1848. This system introduced "land ownership" in Hawai'i and completely altered the traditional reciprocal relationship Hawaiians had established with their 'āina (land) (Cachola 1995, 87-88). Shortly after the Māhele system establishment, the Resident Alien Act of 1850 was passed to allow foreigners ownership of Hawaiian land (Cachola
1995, 93). The Hawaiian Organic Act of 1900, enforced by the US federal authorities, later repealed all konohiki rights and opened fishing to all persons. Due to these policy changes, few parts of modern-day Hawai'i abide by the customary system. Yet, while driving through O'ahu the car often passes signs marking a particular ahupua'a from the past. Many people do not recognize the history behind these signs.

Fishponds tend to be privately owned now, although some located in state parks are controlled by the federal government. Many fishpond workers are trying to receive recognition as fishpond practitioners. This title legitimizes their work and accounts for effort put into restoration. As explained by Interviewee 5, the fishponds on the island of O'ahu organize and meet at least once a year through the organization Kua'âina Ulu 'Auamo (KUA), which translates to a backbone organization supporting grassroots movements. KUA provides space for fishpond 
practitioners to expand their networks and discuss ongoing projects around the islands. They function on a participatory democratic model, where they leave most of the decisions up to practitioners and then work to support the practitioners' projects. The organization facilitates discussions on how fishponds functioned in the past and what they aspire to be in the present and future.

\section{Hawaiian Identity}

Learning the nuances within Hawaiian identity can make the movement for the reclamation of Hawaiian cultural management more accessible. My interviewees (including fishpond practitioners, policy makers, academics, activists, and oral curators), all emphasized how Hawaiian identity sprouts from mythology, spirituality, and sustainability. Glancing into Hawaiian identity demanded building trust between myself and my interviewees before interviewees shared mythologies, or mo'olelo. Mythologies are passed through oral tradition, and each orator adds their own small details. Some mythologies about the fishponds have been lost, and the transcribed mythologies often go un-translated. Interviewee 1 has begun keeping a written, translated record of these mythologies in order to preserve them for future generations. Documentation of the myths in English may pique a greater interest in Hawaiian cultural resource management for outsiders. One Uncle (a term of respect used for male Hawaiian elders) recounted the creation mo'olelo (myth) of fishponds.

I came across a legend of $K \bar{u}$, actually a spirit from the sea who took a human form...he noticed that while fishing was great outside of Hana, Mau'i, on the open ocean, there were times when it was, due to storms or heavy winds, so that people could not go fishing. So he thought the people in this ahupua'a were suffering because fish was a main part of their diet. Then he saw nearby an inlet...that if he made a wall on the ocean side of it, it could maintain fish and keep them alive...That was the beginning of the first fishpond in Hawai'i and maybe in the world. (Interviewee 3)

When Interviewee 3 came to fishpond $B$, he immediately set out to find the stones honoring
$K \bar{u}$. In his mind, the restoration of the fishpond could not go forward without these stones. After finding the stones, he had to pull them out of the mud, clean them, and restore them to their proper places. Afterwards, he contacted the Bishop Museum, which is the Hawaiian cultural history museum, to confirm if the stones accurately matched historical records of stones for $K \bar{u}$. The museum confirmed his cosmology.

Another myth explains the origins of fishpond guardians.

They left their lands to come here and they arrived here [fishpond D], they assembled themselves, and then the head mo'o (guardian), the ancestral mo'o Lani Wahine, made a procession... then she just had all these guardians and told them to go find places... find people to take care of you, to honor you and some did. A lot of them they found places, but there was nobody to take care of them, so the name exists [sometimes] but the history is lost. (Interviewee 10)

Interviewee 10's knowledge of this myth is not comprehensive because deterioration of details often happens with oral tradition. Fishpond D tends to pass the mythologies on to interns orally, and written accounts still remain rare for them. One myth describes how guardians take many forms, but always defend their fishpond.

Fishpond A... had a visit with a giant stingray coming in and flipping itself into the fishpond...according to legend, fishpond A was having trouble in the past with poachers... so the kupuna of the fishpond went up to the point in [the mountains] over there where there lived a person of the stingrays... and after he listened to the story he made a gesture and one of the stingrays jumped into the air and made itself like a kite and sailed down and landed in fishpond $A$ and that became the keeper of the fishpond. So when that giant came in the last 10 years... that was the returning of the guardian. (Interviewee 3)

These mythologies play a large part in the rebuilding of Hawaiian fishponds. Respecting the land means practitioners receive protection from guardians. If the land is abused, the 
guardians will punish the trespassers. This encourages Hawaiians to take good care of the land, nurturing it and molding it to coincide with nature.

Practitioners still try to honor their mo'o by offering prayers, shells, and wreaths of flowers to them, even the ones with unknown names. These traditions, which unite fishpond workers and continue a tradition of respect, show that spirituality continues to fit into Hawaiian identity and fishpond management. Their spirituality encourages them to work with the resources in and around the fishponds, rather than making decisions that solely benefit humans. This is why guardians appear to people in forms of animals or other life forms from the natural world - to nurture appreciation toward these beings. Traditional management encourages similar reverence for the land: "land is the chief and we are the servants to the chief" (Interviewee 3).

The prayers recited to guardians and the chants recited before entering fishpond grounds are referred to as oli. An Uncle on the island of Moloka'i shared that oli can mean different things for different people; regardless of these varied meanings, oli is an integral part of most indigenous peoples' interactions with fishponds and practitioners. Among fishpond practitioners, oli is so crucial that it has taken on many more meanings than the literal translation in a dictionary. This reveals the transformative powers of cultural resource management as an adaptive practice. For example, when asked why oli holds such significance in fishponds, Interviewee 10's explanation connected with culture, mythology, and the earth's resources. "If you don't get a response you gotta keep [going], you have to oli again and oli again. So it depends on those who are inside and if they feel like it's not wellreceived" (Interviewee 10).

Something as simple as a greeting has many nuances behind it. These olis are an integral part of many fishponds and also reference the ethics of sustainability: nurturing and caring for the land. Sustainability in local terms reflects the standards of ahupua'a land division, and each interviewee spoke about this management.

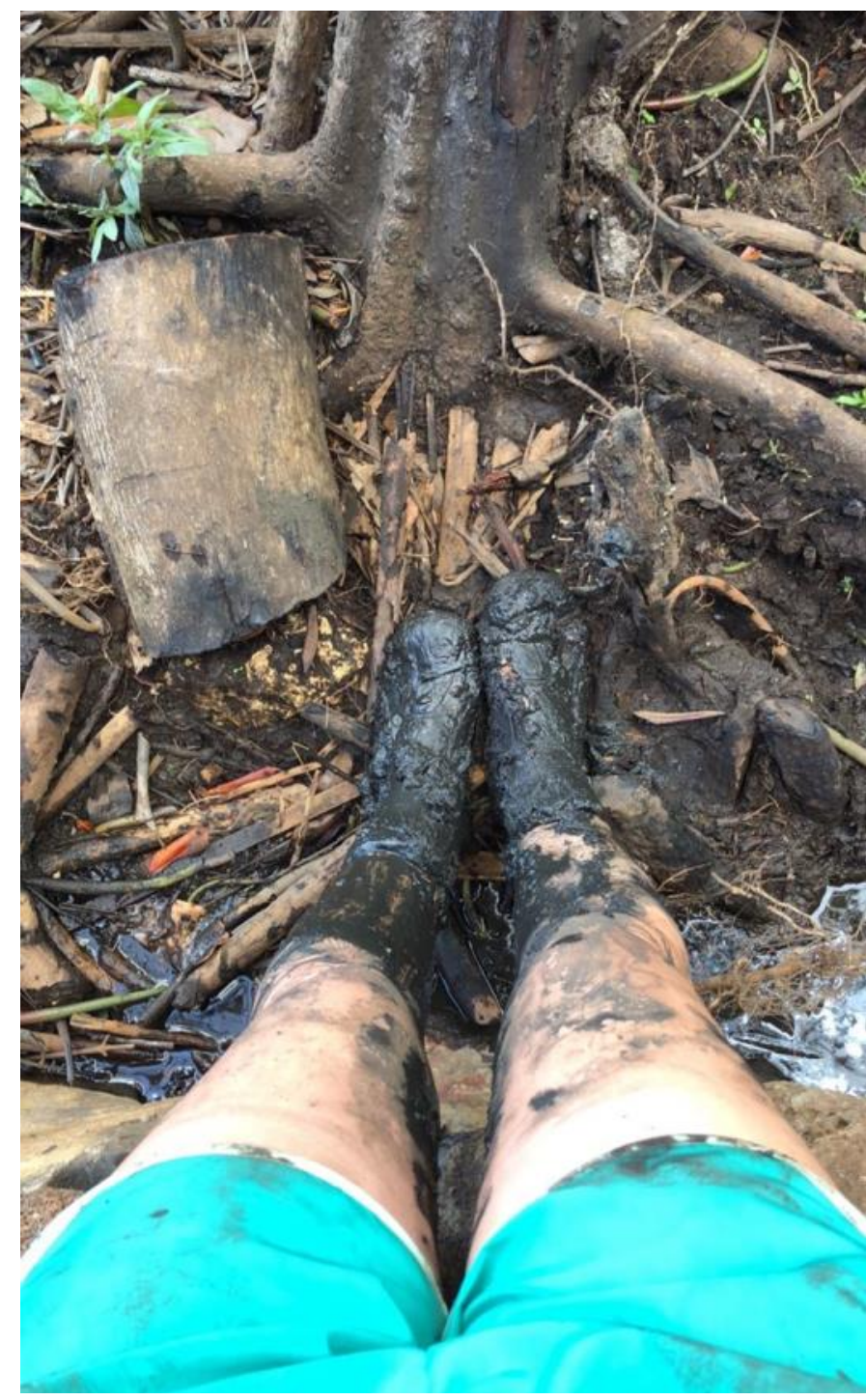

Figure 4 - Photo of my feet after completing a workday. Photo by Evelyn Cornwell.

Indigenous systems of management far surpasses Western management...These things are not a resource but a part of kinship... These fish are all ancestors, along with all the plants and animals and mountains. There is a reciprocal relationship: we take care of the fish and they take care of us. Our success is dependent on the fishes' success. (Interviewee 1)

This connection to mythology, spirituality, and resources guides practitioners to sustainable choices. As I came to understand this connection, I learned that it is the reason they choose to be called fishpond practitioners. Recognizing their relationship with the environment as a reciprocal one, they work with the fishpond while practicing respect and understanding. 
In Hawaiian culture there is our kumulipo, our ancient creation chant, and you see in that genealogy connection... that there's other species, marine and terrestrial, that are born and they're all our brothers and sisters or they're our ancestors above us and so if they're family, then you have a moral obligation to care for them. (Interviewee 4)

Clearly objectification of the natural world is not a workable model of sustainability. When people view resources as a source for gain, they often do not consider the value of that resource or feel grateful for what the resource provides them. Fishpond practitioners have an alternative viewpoint because their model of sustainability directly correlates with Hawaiian identity and community involvement.

\section{Community}

Communities surrounding fishponds have different levels of involvement, which range from daily involvement to having little or no interest. Even the communities involved in restoring the fishponds do not always understand or enact traditional values such as ahupua'a when interacting with the area. However, despite these different understandings and levels of engagement, many individuals are coming together and working as a community to restore these areas.

Most of the five fishponds that I visited during my fieldwork are open to the community for workdays. Workdays are opportunities where anyone can visit a fishpond to assist with current projects, varying from tasks such as weeding to helping rebuild fishpond walls (see figure 4). These days provide the fishponds with more hands for restoration projects. Yet, many community members remain unaware of workdays. Their limited knowledge of fishponds may have less to do with not valuing fishpond culture and more to do with the discomfort or difficulties that come with engaging in the culture. I experienced this first-hand as an anthropologist trying to gain access. While I had many positive interactions at fishpond sites, I also experienced outsider treatment.

A representative of KUA, an organization supporting fishponds, elaborated: "I think community involvement is complex, and understanding the really diverse community that we have in Hawai'i now is really complex because there are people who have not had generations of family here" (Interviewee 5). Following this point of view, some fishpond practitioners misconstrue the necessity of Native Hawaiian roots or indigenous roots to build up fishponds and fishpond communities. In reality, success might come through combining the diverse communities of Hawai'i to enact and adapt the sustainable practices of Native Hawaiian management in the present.

An academic at the University of Hawai'i at Manoa elaborated further. She explained how some people today take advantage of the label "Native Hawaiian" and use it as an excuse to get away with detrimental practices to the pond or as an argument for being able to take as much fish from the pond as they want (Interviewee 4). This mindset is tricky since it is similar to the mindset of poachers who come and steal from the ponds. Illegal activity, such as poaching, interferes with tracking and data retrieval from the fishponds. This data is essential for practitioners in analyzing the ecology of the fishpond and is especially vital during restoration processes.

Some fishpond practitioners feel as if there is no hope for the adults of the community because "adults are stuck in their ways [and] the kids will be making laws and decisions in the future" (Interviewee 1). Therefore, many practitioners focus on the youth. Fishpond D primarily focuses on youth programs to pass down knowledge of fishpond management, often doing programs with the Kamehameha Schools, which host private lessons for Native Hawaiians. While it is important to pass on such knowledge, this also limits the scope of community involvement, especially considering current Hawaiian demographics. The most recent demographics show "the racial diversity in Hawaii stands at 38\% Asian, 25\% Caucasian, $23.8 \%$ two or more races, $10.2 \%$ Native Hawaiian/Native Islander, $1.8 \%$ African American, and 1\% other races" (World Population Review 2018). But, according to estimates recorded by David Swanson, a sociologist, the Native Hawaiian population is actually on the rise (Demby 2018). Still, it remains important to include other community members since they compose a large portion of the Hawaiian community. 
Government organizations try to support community interactions with fishponds through public sector meetings. However, getting people to participate is difficult and often requires incentives. As I found throughout my interviews, the general public looks at such meetings as being a hassle or too timeconsuming. Fishpond practitioners often avoid such meetings because they believe that either they will glean nothing from government affiliates, or their presence will spur the government to insert itself further into fishpond management, resulting in more hindrances for practitioners. For fishpond practitioners, enacting similar tactics proves difficult because of resource limitations stemming from private ownership and operation. Fishponds enact community building through workshops, but these workshops only occur occasionally since funding is limited. Non-indigenous community members do not often receive invitations to these workshops. A more inclusive workshop structure might expand community mobilization and support for both existing fishponds and fishpond restoration.

Sometimes the community does successfully mobilize, and state officials work with them in order to make new rules. An interviewee working at the Division of Aquatic Resources (DAR) listed several community mobilizations that involved government assistance. While efforts have been made by the Department of Land and Natural Resources (DLNR) in Hawai'i to create community-based co-management for fisheries, an initiative known as Hawai'i's Community-Based Subsistence Fishing Area (CBSFA), these attempts have only had minor success (Levine 2014). Despite the legislation change enacted in 1994, only one community has successfully implemented a plan in the waters off of Hā'ena, Kaua'i (State of Hawai'i 2014), and Mo'omomi currently has a proposal being assessed (State of Hawai'i 2017). The progress of implementing CBSFAs has been much slower than similar strategies implemented in American Samoa. This is because the DLNR has been particularly tricky to work with for Hawaiian communities, as they provide little to no guidance when it comes to setting up a CBSFA. The lack of guidelines leads to disputes among the Hawaiians trying to create plans for a CBSFA (Levine 2014).
Having the community on the side of fishpond practitioners encourages the government to implement rules and regulations in favor of the community. Community involvement is low for many fishponds, and they hope to obtain more staff members in order to supervise more community workdays. Yet, Interviewee 1 said he still believes progress for fishponds is increasing. "For example, for the moi(type of fish), state laws say they are off limits from June 1st to September 1st (spawning season). There is also more awareness of ocean depletion" (Interviewee 1).

As community involvement is a linchpin for success in this model of sustainability, parts of the community without indigenous ties or previous experience in cultural resource management need to be included. It is important to include these parts of the community in order to gain the support of all those interested in sustainable options for restoring natural resources. Enlisting the help of the indigenous and non-indigenous parts of the Hawaiian community will strengthen the movement and expand the effort of restoration work. Since many of the fishponds struggle with finding enough volunteers and staff members, reaching out to non-indigenous community members will also increase their labor pool.

\section{Education}

Many interviewees mentioned experiential education as being vital to the restoration and management of fishponds. Interviewee 2, for example, explained part of her job as an alaka'i, or fishpond practitioner, is to continually build upon the foundation of education at the fishpond. She is dedicated to her role as alaka'i despite working a daytime job to sustain her family. "Sharing that education with the community so that the cultural practices can continue and bring awareness to others" is a mission statement for her. For this reason, part of her mission has been molding hands-on educational programs in order to pass along the cultural knowledge behind fishpond management. She works to incorporate traditional cultural values such as oli into the educational programs at the pond.

Interviewee 1 claims that their educational program stands out because they emphasize 
the importance of education, cooperation, recruitment, and teaching youth fishpond management. He hopes to share their programs with other fishponds in order to promote community building and mobilization. While not all fishpond practitioners are as open to this transfer of knowledge, each interviewee expressed some interest in doing so.

Gaining government support may increase resources fishponds need for educational programs. An agent at the Division of Aquatic Resources (DAR), a branch of the Hawaiian Division of Land and Natural Resources (DLNR), agreed with fishpond practitioners' promotion of education at fishponds. He spoke at length on the importance of including Native Hawaiian historical cultural knowledge in education and utilizing it to push for more policy change and activism. The depth of his cultural experiences and his vigorous application of academic knowledge combine to make him a particularly effective advocate for indigenous activism and policy-making.

In my agency, we do understand that the take of fish is very important to our islands... it's vital... to perpetuate culture and all of the benefits that fish bring to our culture. We gotta get that balance of letting people take but also making sure there's enough to take for future generations. (Interviewee 6)

He hopes to influence others in his field to similarly dedicate themselves to the mission of adaptive cultural resource management by bridging the gap between policy-makers and indigenous activists and successfully being an advocate for both.

A representative of the organization KUA stressed the importance of fishpond practitioners coming together to focus on core educational values. Uniting on this front would allow for fishpond practitioners to share their teaching methods with one another and grow together, not separately. This will help to create unity throughout the widespread community on the island of O'ahu and to create a more comprehensive understanding of fishponds. Education cannot account for the full revitalization and management of fishponds, but it will create a knowledgeable group of future practitioners.

\section{Policy}

Interviewee 4's account indicates that leadership structures must be altered in order to include place-based management using traditional methods from indigenous cultures. It would involve including indigenous voices in policy-making and building upon educational institutions by adding a curriculum about cultural resource management and its sustainable impacts. These changes would help to create a model of adaptive management.

So the ali'i and the konohiki, the chiefs and their overseers, they needed to have a good relationship with the people cause the people had the right to leave if they didn't like their chiefs - so that person [the konohiki had to be charismatic, had to have leadership qualities and integrity by which they could inspire the people. (Interviewee 4)

The charisma required in konohiki of the past seemed reminiscent of Interviewee 6 . Interviewee 6 refreshingly offered transparency on the subject of policy, as government organizations do not always present themselves so candidly. His passion is obvious, and he has friendly ties with his coworkers and fishpond practitioners. Yet, he is not in a powerful position at the Division of Aquatic Resources (DAR). Including more indigenous peoples like Interviewee 6 in government positions could create a positive change. As an indigenous activist and government official, he has friendly ties with his coworkers as well as with fishpond practitioners. Often his practitioner friends talk with him when they have concerns over policies or government intervention. Speaking with government officials can be difficult for practitioners because they feel misunderstood and marginalized; as such, a more diverse office that includes representation of diverse voices can lead to more trusting relationships between officials and practitioners, similar to the relationships Interviewee 6 has garnered.

An employee for the National Oceanic and Atmospheric Administration (NOAA) made it clear that government agencies do not fully grasp the merit of cultural resource management. Interviewee 8 even tried to put a number to indigeneity: "What I'm curious about 
is the definition of Native Hawaiian, because... I want to say that there is a percentage of indigenous or what defines an indigenous or Native Hawaiian to what percentage of your lineage or your heritage" (Interviewee 8). This may be a problematic viewpoint as it has the potential to obscure the importance of cultural definitions of indigeneity by focusing on percentages of bloodlines. He wants to be able to quantify what it means to have indigenous roots, but quantifying indigeneity precludes those who support indigenous perspectives without indigenous ties to them. Quantifying indigeneity could make those who are unsure of how much Polynesian or Native Hawaiian blood they have question their authenticity. This drive to quantify is particularly problematic when fishpond practitioners are pushing toward a cultural revival that includes support from those who identify as Native Hawaiians but may not know if they have Hawaiian bloodlines and those who value indigenous culture but may be non-indigenous people. This movement of Hawaiian cultural resource management is, therefore, not defined by numbers.

When asked how traditional resource management plays into NOAA's work, Interviewee 8 stated that the option for cultural resource management is not something that affects the daily jobs of government employees: "Let me pause and think about this. Because my initial reaction is that it doesn't (Interviewee 8)." He did state that it may be part of the work done by a few employees at NOAA, but it has not been taken into larger consideration. Fishpond practitioners note that the government does not often involve itself with the fishponds. For example, one practitioner stated, "until there is a shift away from tourism and development and they turn towards feeding the population, [it won't change]" (Interviewee 1).

Interviewee 8 argues today's government cannot support Hawaiian fishponds in the way practitioners want to manage it. The kapu (forbidden) system was used to deter citizens from certain actions in the past and involved very severe punishments. Interviewee 8 did not think Native Hawaiian fishing practices could function under international law because of traditions such as the kapu system. "They're trying to draft laws that grant privileges to the Native Chamorro. And if you try to do the same thing for the Native Hawaiians, it doesn't fit the current system of government that we have" (Interviewee 8).

Yet, fishpond practitioners are focused on reviving the resource management strategies that were in place and not the punishment. He did not fully understand this because, in the context of the kapu system, an adaptive resource management would be unattainable. However, in the context of sustainability, spirituality, and education, it is attainable.

His justifiable confusion is indicative of the confusion of many policy makers when attempting to grapple with the complexities of cultural resource management, as well as overlapping local, state, and federal jurisdictions. Interviewee 12, an indigenous activist, stated that across Hawai'i "fishponds, springs, taro fields, and wetlands [are] valuable because all waters below high water mark belong to the public." Perhaps for this reason, state organizations seem to work more closely with local communities in wetland management. For example, the Office of Conservation and Coastal Lands (OCCL), part of the Hawaiian Department of Land and Natural Resources (DLNR), has done some recent work with fishponds. This state-level branch of DLNR created a more effective policy for fishpond restoration. Interviewee 6 , who works closely with OCCL, elaborated on OCCL's work.

They have this one stop shop for fishpond restoration so it kind of gives them a break on some stuff and makes it easier for them to address all the parties who may have interest in what they're doing, all the agencies they may have to get permission from and stuff like that. (Interviewee 6)

This permit application can be found on OCCL's website and is a simple five-page document. This streamlined application was released by DLNR in January 2015, four years after its conception (Office of Conservation and Coastal Lands 2018). Unfortunately, this streamlined process does not provide solutions for all fishpond challenges. 
One fishpond knows about the streamlined application for fishpond restoration but cannot use it for the restoration they want to enact. Interviewee 10 expressed his gratitude toward an older man in the community who obtained approval for their restoration project. Since the project did not fit into the streamlined process, this Uncle used his connections to get the proper permits. Not every fishpond has similar connections, which means that the permitting processes not accounted for in the streamlined application still take extended periods of time to accomplish. Furthermore, completing an application does not guarantee the fishpond will be approved.

Due to the policies of the current US administration, funding from the federal government and the Environmental Protection Agency (EPA) is slim. Many privately owned fishponds receive grants from the federal government as a way to budget for restoration. The cutbacks on EPA funding reduces grant opportunities, thus hurting the ability of practitioners to continue their work. On top of these funding cutbacks, Hawai'i is expected to provide fish for much of the United States. Interviewee 6 expressed how this makes regulation throughout the islands even more difficult: "Our fish feeds the people in the states, too. For the amount of people we have in the US and the amount of power we have, our quota is so small compared to other places like Japan, China, Philippines, [and] Indonesia" (Interviewee 6).

This fits in with the overall marginalization of Hawai'i in federal policy-making. Many resources come from Hawai'i, and people on the mainland often forget this. As put by Interviewee 9 from the Western Pacific Regional Fishery Management Council (WESPAC),

A lot of the times you see... a romanticized view of what Hawaiian [indigenous] life was like.... Because of the way the system is, you'll never be able to go back to those types of systems...While we can't go back to saying Hawaiians only... what you can do is say, there are people with the knowledge, about the fishery or about the resources, if they're Hawaiian, or if they're not Hawaiian, it's [about] that process of coming together and talking about it, and providing what's best for the area. (Interviewee 9)

Fishponds deserve more funding for restoration because they contain cultural and practical value. Once functional, the fishponds could provide local sustainable food sources for the population of Hawai'i. One of the fishpond practitioners elaborated how much fish can be produced on site: "[in] a fishpond for every acre, you should be able to supply up to 500 pounds of protein" (Interviewee 2). In addition, fishponds provide significant benefits in terms of processing waste through natural filtration, such as oysters, restoring depleted fish stocks, and reviving native species while combatting invasive ones.

Despite the drawbacks of poaching in fishponds under restoration, Interviewee 8 believes all people have a right to fish at all times. His statement brings to mind Interviewee 4's discussion of entitlement, where Native Hawaiians felt as if they had the right to take fish because they grew up on the land. But this is not a model for sustainability. Given historical context, a uniform treatment under the law may not result in equality, justice or sustainability for both indigenous and nonindigenous people. If the federal government adopted state-level initiatives and tried to work with the fishponds using adaptive management, they might realize that replenishing fish stocks will provide a steady stream of food to the community, both now and in the future. This may include making certain areas off-limits as they recover and replenish.

WESPAC provided assistance to fishpond $A$ in its beginnings, but it did not carry on this involvement. While fishponds could become a key source of sustenance for the community, WESPAC considers sustainability to be about keeping everyone fishing. Rather than replenishing fish stocks or looking toward feeding future generations, they focus on keeping fishermen fishing. "For us sustainability is really about keeping people fishing, it's not necessarily keeping so much fish that we can have for everything" (Interviewee 9).

This is a wildly different understanding of sustainability from that of fishpond advocates. Fishpond practitioners are pursuing restoration 
in an effort to replenish the ever-depleting fish stocks. Many indigenous activists are also calling for certain limitations or restricted fishing areas in order to allow ecosystems to recover. In contrast, WESPAC is not looking toward the future but is focused on current commercial gains. WESPAC's strategy for fisheries management puts too much focus on keeping fishermen out on the water now and not enough focus on saving resources for future generations. This approach will, in the long-run, lead to the depletion of resources and the loss of biodiversity.

The NOAA website lists six key components of the Magnuson-Stevens Act, which WESPAC refers to as their ten commandments: "prevent overfishing, rebuild overfished stocks, increase long-term economic and social benefits, use reliable data and sound science, conserve essential fish habitat, [and] ensure a safe and sustainable supply of seafood" (NOAA Fisheries 2018a). Fishery management councils, such as WESPAC, use this act to create fishery management plans (FMPs). The ten national standards referenced each have their own guideline documents and other related resources. These ten commandments each have a rather generic title, but it is notable that "optimum yield" is first on the list while "safety of life at sea" is last (NOAA Fisheries 2018b).

NOAA's site states that these principles promote sustainable fisheries management. Yet, their definition of sustainability seems skewed after speaking with both Interviewee 8 and 9. Fishpond management should be able to fit into this model of analysis, but NOAA continues to avoid making comprehensive plans that fall in line with what fishpond practitioners need. Interviewee 4, an academic and activist, gives insight into why incorporating fishpond management into sustainable initiatives should take precedent:

As we have kind of this global economy, we don't know where our food comes from, out of sight, out of mind, so then you don't have that respect... So the thing with staying in your ahupua'a, you begin to know every feature of it... it's like how you know a family member... and that's why the management works, cause you end up having a love for your place. (Interviewee 4)
So it is adaptive management in the sense that management is adapted to the changing conditions, but, as said by Interviewee 4, "typically the management in our modern times is a very top-down, centralized management system... [but we need to] customize our management to that place" (Interviewee 4). Local, place-based management provides a model for how state and federal authorities can incorporate adaptive management into policymaking. Customizing the policies for different areas and ecosystems creates adaptive models which relieve pressure on resources. State-level policy-making is slow, but there are efforts to work with the community and some advances in working with fishponds. Federal level policy works a bit differently and needs significant improvement to align with the goals of active management of fishponds. Government marginalization of the state of Hawai'i and indigenous peoples continues to be one of many challenges fishpond practitioners face in the work of restoration.

\section{Challenges: Above and Beyond}

Fishponds face many challenges, especially in early stages of restoration. Most interviewees addressed the lack of access to freshwater as a big challenge for fishponds. Estuaries are vital for fishponds; yet, developers tend to block freshwater flows and plug up underground water channels. Interviewee 2 explained the importance of water rights not only for fishpond practitioners but also for indigenous movements across the globe. "Not having access to freshwater, one: is detrimental because... we don't have freshwater anymore coming into our ponds so we really need freshwater [for these fish], and two: it's our right as cultural practitioners to have access to that" (Interviewee 2).

Interviewee 2's recognition of other indigenous communities facing similar issues emphasizes the frequent marginalization of indigenous communities. Practitioners deserve recognition from the state of Hawai'i and the federal government, especially when considering that fishponds could yield 500 pounds of local food per acre once restored. Yet, practitioners are not allotted the resources they need. 
The Western Pacific Regional Fishery Management Council (WESPAC) is meant to support indigenous efforts in the community, but they do little to support the fishponds of O'ahu. They claim that animosity from fishermen makes it difficult to support ideas such as CBSFAs (Community Based Subsistence Fishing Areas), where the community regulates and creates rules for fishing areas in conjunction with the Hawaiian government. WESPAC's concern for the big business of fishing versus the small, sustainable growth of fishponds seemed to contradict their mission to support community based management and indigeneity. WESPAC barely helped with the successful implementation of a CBSFA in Ko'olawe, despite receiving credit for it. "We didn't have anything to do with the one in Ko'olawe, even though everyone says we did" (Interviewee 9). This statement shows CBSFA management is not the route for fishponds. It has proved largely unfruitful in the past and requires a revamped approach for fishponds to receive the assistance they need.

Most fishponds face the same challenge of lack of staff and resources. Due to being privately owned, many of the fishponds lack financial means to support more staff, especially at a competitive rate. This means some fishponds have as few as two paid staff, and the rest of their help comes from volunteers. Interviewee 2 illustrated the merit of paid staff by talking about the most employed fishpond on the island.

They have maybe 8 employees that are paid and they have an internship program. And a lot of that is because they have support through [a local educational organization], so every year they're given a certain dollar amount and then what they do is they raise money through fundraising to supplement that budget... (Interviewee 2)

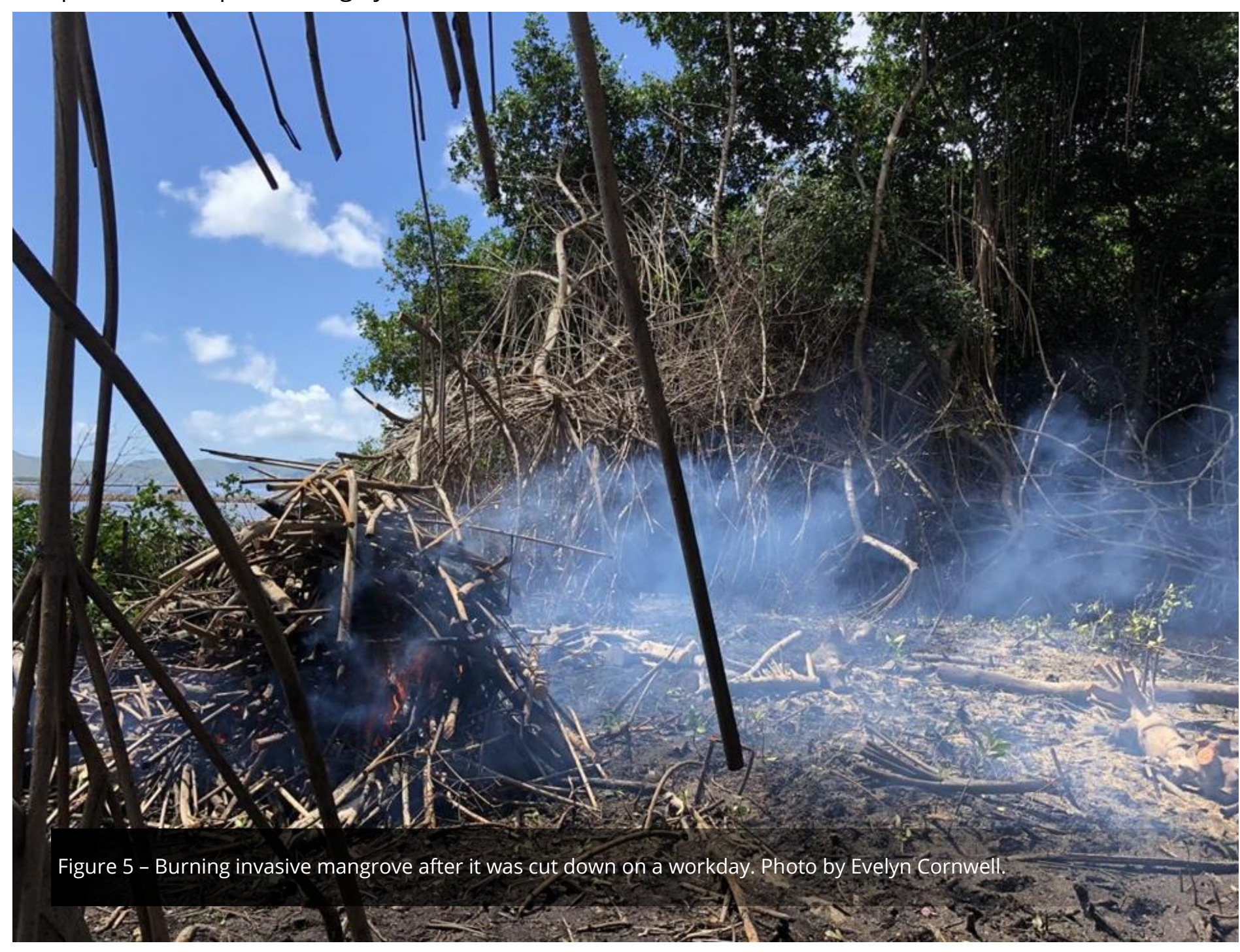


Fishpond $A$ is at the forefront of fishpond restoration on O'ahu, and many fishponds look to them as an example. Despite their personal progress, Interviewee 2 said they do not make time to help other fishponds. Fishpond B particularly struggles with finding enough resources for restoration and often gets turned down when asking fishpond A for guidance. Fishpond $B$ now gets help from rural Hawaiian Islands, such as Moloka'i and Kaua'i, who are more likely to take time out of their schedules.

Due to lack of funding, some fishponds produce and sell oysters or fish to support fishpond restoration. In order to begin raising oysters or fish, the water quality in the fishpond must be safe enough for people to consume seafood from it. Due to pollution caused from runoff, erosion, and other outside factors, this is a laborious process. Practitioners have to fight off invasive species in the pond that threaten the oysters or fish. Then they must figure out methods to prevent barnacle or other parasite growth (Interviewee 7). Oysters naturally filter water, making the fishpond cleaner and healthier for fish and organic life. Fishponds that cannot support oyster propagation often sell invasive species for profit. Clearing the fishpond of invasive species and predator fish ensures the protection of native, herbivorous species.

Another huge threat to fishponds is the invasive growth of mangrove in the ponds. I spent an entire day clearing mangrove from one fishpond (see figure 5) and pulling mangrove seedlings from another. Many people are surprised to discover that mangrove is invasive in Hawai'i since it is beneficial to the environment in many places around the world. "[Mangrove] is not good for the native fish and the native seaweed because it suffocates them, it takes all of the oxygen from the pond" (Interviewee 2). This removal work is time consuming and exhausting, but the potential for sustainable food systems and the repurposing of mangrove into furniture and other items makes these strenuous efforts worth it.

Many fishponds face individual, site-based challenges. In one case, a fishpond struggles with sand build-up within the pond. Although they dig the excess sand out to increase the depth of the pond, the city does not allow them to transfer the sand elsewhere nor sell it to landscapers. This leaves fishponds stuck with low water levels due to high sand quantity. When a fishpond has shallow water, less oxygen is produced within the water and the water heats up quicker. These conditions cause the fish to become too warm and their sluggishness prevents them from escaping predators. It also stunts plant growth within the pond, decreasing food options for selected herbivorous fish. Understanding the impacts of sand build-up made volunteers more motivated to contribute on workdays.

One fishpond faces significant challenges in managing pollution from wastewater treatment plants and other upstream contaminants. This same fishpond cannot afford to pay for on-site staff 24/7, leading to greater amounts of poaching and theft. The fishpond goes unchecked throughout the week because staff also have regular 9 to 5 jobs during the week. This has led to fish die-offs when raising pua (baby fish). Big companies located nearby often try to buy the fishpond land or control their resources. Moreover, this fishpond is tucked into a hard to reach location, so many people in the community do not realize it exists. This contributes to low turnout on workdays when they desperately need help.

Overcoming the geographic challenges on O'ahu would help create a united front for fishponds. O'ahu is the most urban island in Hawai'i; therefore, the people of O'ahu often get wrapped up in their fast-paced lives and are less likely to make time for workdays than people on more rural islands. Because it is harder for O'ahu fishpond practitioners to meet when working multiple jobs and caring for families, fishpond meetings occur infrequently. Yet, interviewees think face-to-face interactions are vital. Despite the importance of meetings, it is difficult to organize them and get approval from government agencies to go forward with plans formed at the meetings. This means that even if a meeting occurs, conversation between practitioners may be the only thing gleaned.

In an urban setting, practitioners also have a larger pool of people to appeal to and gain assistance from. 
What is happening in these urban centers is that there's such a craving to understand how our elders and our ancestors did things, like its essential to our culture and our identity and our well-being, so when you live in a place like O'ahu where you see a lot of concrete jungle basically, just to get back to who you are as Native Hawaiians means you got to go and put your hand in the soil again or work at the fishponds. (Interviewee 4)

Others in the community are also beginning to yearn for more revival of natural diversity within the ecosystem. As climate change affects the globe and natural resources deplete, people in both urban and rural areas are turning to traditional methods in order to live more sustainably. Fishpond restoration is one of those methods. As the push to shop local, buy organic, and consume more 'natural' products increases, more people are willing to explore indigenous methods of sustainability. During workdays, indigenous people were not the only ones sticking their hands back into the soil. People from nearby neighborhoods stopped by, parents brought their children, and travelers from around the world participated. This mobilization of the whole community could substantially impact government opinions and lead to more efficient policy changes.

\section{Conclusion}

Based on fieldwork and interviews with oral history curators, academics, activists, government officials, and indigenous alaka'i (practitioners) involved in the revival of traditional fishponds and ahupua'a (land-based management systems), I provide a case study of the politics of cultural resource management on two islands in Hawai'i. In particular, my research underscores the need to combine multiple models of sustainable practice in order to make adaptive cultural resource management possible. This model would combine cultural resource management, historically based restoration, Community Based Subsistence Fishing Area (CBSFA), and Traditional Ecological Knowledge (TEK). As suggested by Tony Pitcher and Mimi Lam, combining independently successful models of sustainability should result in a more successful model. Based on informants' understandings of place, culture, and politics in their own lives, the ideal model for a sustainable global future should be based, in interviewees' own terms, on an indigenous place-based model of "adaptive" cultural resource management.

This model is distinguished by conceptions of identity, community, education, and spirituality. At its core is the conception of the natural world as an active, adaptive subject rather than an object of management. Exploring Hawaiian identity provides a new outlook on resources by recognizing them as kin and, as such, treating them respectfully. The discussion of community brings to light the importance of uniting people, indigenous and non-indigenous, to reach a common goal. Without educating future generations, policy makers will not change and no one will be left to continue the work of fishpond practitioners. Policy makers need to seriously consider the positive effects of adaptive cultural resource management and take more risks. They currently function without making many changes and tend to write-off indigenous viewpoints. They need to be examining every option available to make resource management more sustainable. Despite the many challenges fishponds face, there is merit in contributing resources to the pursuit of restoration. In conclusion, indigenous, place-based management systems of fishponds show more effective results in ecosystem recovery and should therefore provide a model for policy and practice in other places. 


\section{Acknowledgements}

I appreciate all 5 fishponds and 15 interviewees who willingly participated in this research and made it possible. Great thanks go to Saint Mary's College in Notre Dame, Indiana, for providing funding for this research through the SISTAR grant. I also extend my thanks to The Journal for Undergraduate Ethnography for helping refine this piece and make it accessible to others. A particularly loving thanks goes to my relatives, the Parslow family, who housed me, supported me, and often accompanied me throughout my research. Thanks also goes to the many friends and family who supported and assisted me throughout this process - especially my boyfriend, Noah Studebaker, who continually encouraged me at my most stressed, and my roommate, Mary Gelder, who regularly soothed my anxieties with tea and cookies. My deepest appreciation goes to Professor Laura Elder, my mentor, editor, and supporter. I will never be able to fully express my appreciation for your guidance throughout this process and the friendship gained from it. 


\section{Appendix A: Glossary of Hawaiian Vocabulary}

ahupua'a - term for traditional Hawaiian socioeconomic, geologic, and climatic subdivision of land

'āina-land; earth

alaka'i - to lead/direct; leader; conductor

ali'i - chief, cheiftess; king, queen, noble; to rule or act as a chief

'Auamo - carrying stick held on multiple shoulders of laborers who shared burden of carrying something of great weight forward

kapu - forbidden

keiki-child, offspring

kua-back; backbone

kua 'āina - grassroots (rural people of Hawai'i)

kuapā-walled

kupuna - elder

konohiki - headman of an ahupua'a land division under the chief

$k \bar{u}$ - to run in schools as fish; name of major god

$k \bar{u}$ 'ula - any stone god used to attract fish; open altar near the sea for worship of fish gods

kumulipo - origin, source of life; name of the Hawaiian creation chant

lawai'a - fisherman; to fish, to catch fish

limu - general name of all kinds of plants living under water (fresh and salt water); algae, moss, lichen, liverwort

lo'i - irrigated terrace, especially for taro

loko - in; inside; interior; to implant

loko l'a - fishponds

Māhele - portion, division; land division of 1848 mākāhā-sluice gates

moku - district; island; section

mo'o - succession, series, especially a genealogical line; guardian

mo'olelo - story, tale, history, tradition, legend, record, myth

oli - chant that was not danced to

po'o - head, summit, director

pua - baby fish

pu'uone-divination; pond near the shore

$u / u$ - to grow

'ula - red, scarlet; sacred

'umeke-bowl, circular vessel 


\section{Appendix B: Glossary of Abbreviations and Acronyms}

CBSFA - Community Based Subsistence Fishing Area

DAR - Division of Aquatic Resources (sector of DLNR)

DLNR - Department of Land and Natural Resources

EPA - Environmental Protection Agency

FMPs - fishery management plans

KUA - Kua'āina Ulu 'Auamo (backbone organization supporting grassroots movements)

NOAA - National Oceanic and Atmospheric Administration

OCCL - Office of Conservation and Coastal Lands

TEK - traditional ecological knowledge

TMK - Tax Map Key

WESPAC - Western Pacific Regional Fishery Management Council 


\section{References}

Bambridge, Tamatoa. 2016. The Rahui: Legal Pluralism in Polynesian Traditional Management of Resources and Territories. Australia: ANU Press.

Cachola, Jean Iwata. 1995. "Land Ownership." In Kamehameha III: Kauikeaouli, 79-87. Honolulu, Hawai'i: Kamehameha Schools Bernice Pauahi Bishop Estate.

Demby, Gene. 2018. "It Took Two Centuries, But The Native Hawaiian Population May Be Bouncing Back." National Public Radio(NPR). Last modified April 18, 2015. https://www.npr.org/sections/ codeswitch/2015/04/18/398578801/it-took-two-centuries-but-thenative-hawaii-ans-has-finally-bounced-back.

Encyclopedia.com. 2019. "Cultural Resource Management." Last modified October 4, 2019. https://www.encyclopedia.com/socialsciences/applied-and-social-sciences-magazines/culturalresource-management.

Leonard, Annie. 2007. The Story of Stuff. Free Range Studios. From The Story of Stuff Project, YouTube video, 21:16. https:// storyofstuff.org/movies/story-of-stuff/.

Levine, Arielle, and Laurie Richmond. 2014. Examining Enabling Conditions for Community Based Fisheries Comanagement: Comparing Efforts in Hawai'i and American Samoa. Ecology and Society 19 (1), 24. http://dx.doi.org/10.5751/ES-06191-190124.

National Oceanic and Atmospheric Administration (NOAA). 2018. "Fisheries." U.S. Department of Commerce. Accessed June 2018. http://www.noaa.gov/fisheries.

Nelson, Melissa. 2008. Original Instructions: Indigenous Teachings for a Sustainable Future. Rochester: Bear \& Company.

NOAA Fisheries. 2018a. "Magnuson-Stevens Fishery Conservation \& Management Act." West Coast Region. Last modified October 12, 2018. https://www.westcoast.fisheries.noaa.gov/whatwedo/msa/ magnuson_stevens_act.html.

NOAA Fisheries. 2018b. "National Standard Guidelines." Laws and Policies. Last modified February 7, 2018. https:// www.fisheries.noaa.gov/national/laws-and-policies/nationalstandard-guidelines. 
Office of Conservation and Coastal Lands. 2018. "Ho'āla Loko l'a." State of Hawaii. Last modified 2015. http://dlnr.hawaii.gov/occl/ hoala-loko-ia/.

Orlove, Ben. 2002. Lines in the Water: Nature and Culture at Lake Titicaca. Berkley and Los Angeles: University of California Press.

Pitcher, Tony, and Mimi Lam. 2010. "Fishful Thinking: Rhetoric, Reality, and the Sea Before Us." Ecology and Society 15 (2), 12. http://www.ecologyandsociety.org/vol15/iss2/art12/.

Ruru, Jacinta. 2012. "The Right to Water as the Right to Identity: Legal struggles of indigenous peoples of Aotearoa New Zealand." In The Right to Water: Politics, governance and social struggles, edited by Farhana Sultana and Alex Loftus, 110-122. New York: Earthscan.

State of Hawai'i. 2014. “Hā'ena Community-Based Subsistence Fishing Area Rule Signed by Governor." Division of Aquatic Resources. Last modified 2019. https://dlnr.hawaii.gov/dar/ announcements/haena-community-based-subsistence-fishingarea-rule-signed-by-governor/.

State of Hawai'i. 2017. “Public Meetings Scheduled on Proposal to Establish a Community-Based Subsistence Fishing Area for the North Coast of Moloka'i." Division of Aquatic Resources. Last modified 2017. https://dlnr.hawaii.gov/dar/announcements/ public-meetings-scheduled-on-proposal-to-establish-acommunity-based-subsistence-fishing-area-for-the-north-coast-of -molokai/.

University of British Columbia. 2018. "Aid for oceans and fisheries in developing world drops by 30 percent: Sustainable fisheries make good sense for jobs, nutrition, and climate change resilience." ScienceDaily. Last modified January 17, 2018. www.sciencedaily.com/releases/2018/01/180117164018.htm.

World Population Review. 2018. "Hawaii Population 2018." Accessed June, 2018. http://worldpopulationreview.com/states/hawaiipopulation/. 